\title{
Physical and Electrochemical Properties of Ni-P/TiN coated Ti for bipolar plates in PEMFCs
}

\author{
Chun Ouyang ${ }^{1,2, *}$, Xinlong Zhang ${ }^{2}$, Mingfang $W u^{1}$, Damao Xun ${ }^{3}$, Pingping Gao ${ }^{*}$ \\ ${ }^{1}$ School of Material Science and Engineering, Jiangsu University of Science and Technology, 212003, \\ Jiangsu, P.R.China. \\ ${ }^{2}$ Nantong Reshine New Materials Co., LTD. Nantong City, Jiangsu, P.R. China. \\ ${ }^{3}$ College of Communication and Electronics, Jiangxi Science and Technology Normal University, \\ Nanchang, P.R.China \\ ${ }^{4}$ State Key Laboratory of Powder Metallurgy, Central South University, Changsha, 410083, P.R.China. \\ *E-mail: ouyc1014@163.com fengyun_gao@126.com
}

doi: $10.20964 / 2020.01 .23$

Received: 5 September 2019 / Accepted: 14 October 2019 / Published: 30 November 2019

\begin{abstract}
Ni-P coatings including TiN nanoparticles are prepared by electroless plating on Ti plate, which is used as bipolar plates of proton exchange membrane fuel cells (PEMFCs). Scanning electronic microscope (SEM) and X-ray diffraction (XRD) are used to characterize the surface morphology and phases of the coatings, respectively. Corrosion resistance of Ni-P and Ni-P/TiN coatings are measured in the simulated solution of PEMFCs. The interfacial contact resistances (ICR) between carbon paper and bipolar plates are conducted by applied different forces. Potentiostatic polarization tests are prepared at different voltage by bubbling air and $\mathrm{H}_{2}$ at $70{ }^{\circ} \mathrm{C}$,respectively. It is indicated that TiN particles as a core enclosed by Ni-P are entrapped into the coating by SEM images. Comparing to Ni-P coatings, the Ni-P/TiN coating shows better behaviors of corrosion resistance and low ICR. The good corrosion resistance is attributed to the formation of coating and the compact surface morphology. Hence, Ti metal with electroless plating Ni-P/TiN coating is a potential candidate for applying in the bipolar plates of PEMFCs
\end{abstract}

Keywords: TiN nanoparticles; Electroless plating; Bipolar plates; Ni-P alloy

\section{FULL TEXT}

(C) 2020 The Authors. Published by ESG (www.electrochemsci.org). This article is an open access article distributed under the terms and conditions of the Creative Commons Attribution license (http://creativecommons.org/licenses/by/4.0/). 